\title{
Coronavirus (COVID-19) and Online Learning in Higher Institutions of Education: A Survey of the Perceptions of Ghanaian International Students in China
}

\author{
John Demuyakor ${ }^{{ }^{*}}$ \\ (iD) 0000-0002-6084-6951 \\ ${ }^{1}$ Institute of Communication Studies, Communication University of China, Beijing, CHINA \\ *Corresponding author: tevezkanzo@outlook.com
}

Citation: Demuyakor, J. (2020). Coronavirus (COVID-19) and Online Learning in Higher Institutions of Education: A Survey of the Perceptions of Ghanaian International Students in China. Online Journal of Communication and Media Technologies, 10(3), e202018. https://doi.org/10.29333/ojcmt/8286

\section{ARTICLE INFO}

Received: 16 Apr. 2020

Published: 16 May 2020

\section{ABSTRACT}

The first quarter of 2020 is a hard time for the global community. The Coronavirus (COVID-19) pandemics swept through the world affected many aspects of human endeavour: from the decline in industrial production to the re-adjustments in the academic calendar of all educational institutions globally. Stakeholders and management of higher educational institutions have no other option but to make use of internet technology, thus online learning for the continuation of academic activities across all schools worldwide.

This paper aims at assessing whether Ghanaian international students in China are satisfied with the " mass" online learning in higher educational institutions in Beijing, China.

Therefore, this study employed an online survey to investigate the level of satisfaction of online learning in higher educational institutions and how Ghanaian international students are coping with these "new initiatives".

The findings from the study suggest that the implementation of online learning programs was a very great idea as the majority of the sampled students supported the initiative. The study also revealed that students have adequate knowledge of the COVID-19 pandemic. Another finding that came up during the research is the high cost of participating in online learning. However, our results showed that students outside China due to the COVID-19 spend so much money to buy internet data for online learning. Last but not least, the study discovered that internet connectivity was very slow for students leaving within the dormitories of various universities in China.

The findings from this study will be of much benefit to university administrators and management in taking future emergency decisions concerning the implementation of online learning programs for student's different backgrounds.

Keywords: online Learning, COVID-19 pandemic, higher educational institutions, China, Ghanaian international students

\section{INTRODUCTION}

"Never before have we witnessed educational disruption on such a large scale" said UNESCO DirectorGeneral Audrey Azoulay (2020). The global academic calendar has been thrown into a state of disarray by the Coronavirus outbreak. Most schools from basic to universities have shut down their doors and students have returned home to their parents and together self-quarantined (UNESCO, 2020). Convocations and Graduations have been cancelled, and some classes have been cancelled, some examinations have been cancelled; university research programs have been postponed. Leaders around the world are struggling with the decision to finish the spring semester in most cases. Coronavirus (COVID-19) related decisions will forever change the course of history, so it must be thoughtful and accurate.

Copyright (c) $\mathbf{2 0 2 0}$ by authors; licensee OJCMT. This article is an open access article distributed under the terms and conditions of the Creative Commons Attribution License (http://creativecommons.org/licenses/by/4.0/). 
Most academic heads are now promoting online education as a solution to this crisis (UNESCO, 2020). It is necessary to acknowledge the fact that online education is not an ad hoc solution to face-to-face delivery. Bigger universities over the past decade are gradually moving their programs online and doing away with face to face delivery (Bao, 2020). Top universities in the world such as Tsinghua, Peking University, Harvard, MIT, Yale, Oxford, Cambridge, among others are moving in this direction (Bao, 2020; Picciano, 2017).

Bao (2020), and Filius et al. (2019) argue that going entirely online requires significant planning and investments from all sectors. So, if the university has not hitherto taken the students and instructors through an online teaching training, and may not have enough resources including recording platforms both on campus and at home to get the instructor to record and present the work in a manner that can be accessed by students, then the online plan ends right here (Yang \& Li, 2018). Therefore, before institutions decide to use online to teach in this Coronavirus (CONVID-19) era, they should evaluate this issue very well, such as posting PowerPoint slides for students to read does not constitute online teaching. Suppose the university has a robust online platform and the instructors can record and present the material for students to access even from their homes and, if students do not have the means to access these materials such as a laptop/tablet or a good phone, then they are stuck (Filius et al., 2019).

\section{LITERATURE REVIEW}

The immediate sending of the university students packing and closure of all the campuses across China and other parts of the world has enhanced the virtual delivery of a big number of courses. However, there has been a number of unavoidable problems of teething. According to the observers, there is a likelihood that the future might have become the present (Bao, 2020; Donitsa-Schmidt \& Topaz, 2018; Filius et al., 2019). Within two decades, there has been advancement in the use of technology in the field of education. There have been increased levels of sophistication and effectiveness in a number of schools that have embraced digital learning (Murphy, 2020). According to UNESCO (2020), over 1.5 billion learners in 165 countries are attracted by COVID-19 school closure. This translates to $87 \%$ of the world's student population.

According to another survey conducted by an education think-tank the 'Times Higher Education", on the prospects of higher learning from the perspectives of leaders of major universities in the world in 2018, about 200 respondents drawn from 45 countries across the 6 continents pointed to a specific fact; online education cannot match the normal teaching method. However, 63\% predicted that by 2030 most prestigious universities will be offering their full courses online. However, only $24 \%$ agreed that electronic learning would be more popular than traditional methods of learning.

Technology will reshape the universities by 2030. Though the online system of education is viewed as relatively new, according to research, in the future, it will just be as effective as school-based methods (Murphy, 2020; UNESCO, 2020). The US Department of Education analyzed more than 1,000 learning studies. It was discovered that students who take their course online outperform classroom-based students across most subjects as well as demographics. One other review that was published in the same year discovered that online students had the advantage of time, and according to the authors, the gap is likely to widen with the evolvement of programs and technologies.

Higher learning education has been pushed into experimenting e-learning within an unprecedented scale, and scope as the medical staff members in various universities try to find solutions to an epidemic that had let to more than 100,000 people being infected with COVID 19 virus and about 4000 succumbing to the disease (UNESCO, 2020; WHO, 2020).

In the Chinese mainland, all the students right from kindergarten to doctorate level were asked to stay home and continue with their learning activities online. This was after the Lunar New York break came to an end in January. The pandemic affected 30 million learners at tertiary level in about 3000 institutions. According to (Bao,2020; UNESCO, 2020), many of these institutions have rushed and established online classes to try to fill the void that is like to last for the rest of the academic year in areas that are adversely affected. Not only had the Chinese students been affected by the pandemic but also other students from other countries. Almost half-million international students retreated to their countries and had to log in from their homes to continue with learning and to access the necessary learning materials (Bao,2020). Meanwhile, other countries in the world are also seeking online solutions for their millions of students as a result of the travel ban from 
returning to campus. Higher learning institutions in other regions that were adversely affected such as Italy, Iran, and Singapore were also forced to stop learning and close their campuses and switched to online learning instead of in-person teaching (UNESCO, 2020).

It is important to note that such teething problems can only be experienced due to the high speed through the universities in China have been compelled to shift their mode of teaching online to preserve the health of their students due to the outbreak of coronavirus(COVID-19) that has greatly paralyzed the region $(B a 0,2020)$.

The reports provide a good number of reasons as to why students are likely to learn effectively through online studies. According to the reports, students have more control over their studies and have more opportunities at their disposal for reflection. It is reported that successful online students tend to be organized and are self-starters who can accomplish their work without close supervision (Picciano, 2017; Wang \& Hu,2019).

However, there are numerous complaints among the Ghanaian international students on social media platforms regarding their frustration with online education. There are instances where students have to rush to the toilets to answer calls from their professors or to turn off video feeds because the colleagues are playing and yelling in the background. Other key issues that are of great concern to students part-taking in the online is the effectiveness and credibility of course content for online learning, the issue of availability of learning resources has also come out strongly as well as the level of students' knowledge on the COVID-19. Therefore, this article intends to survey the perceptions of Ghanaian international students on the large scale implementation of online learning in their universities in Beijing, China. To have a solid foundation for this study, our study will be anchored on the following theoretical framework; Online Collaborative Learning (OCL). The objective and research questions will also be considered carefully.

\section{THEORETICAL FRAMEWORK}

There are several theories and models related to the study of online learning, but. For this study, the researchers found Online Collaborative Learning $(\mathrm{OCL})$ to be the most suitable model to be used in this research. The reason behind using Online Collaborative Learning $(\mathrm{OCL})$ is to help understand how students and educational institutions accept and use technology for teaching and learning.

\section{Online Collaborative Learning $(\mathrm{OCL})$}

$\mathrm{OCL}$ is a theory that was proposed by Linda Harasim. The theory focuses on the internet as a source of learning through fostering collaboration and building of knowledge. Harasim describes the new theory of acquiring knowledge as one that is focused on collaborative learning, internet use, and knowledge building. Harasim (2017) can be described as a way of reshaping formal, non-formal, and informal education. Just like Siemens, Harasim (2017), points out that many benefits are associated with moving to teach and learning to the internet and predict a large scale network of education being created from the concept of e-learning. In some instances, he utilizes Alberto Barabasi's point of view on the power of networks. OCL is believed to support three phases of knowledge acquisition and construction. They include the following;

- Idea generating: This is a phase that involves brainstorming. In this phase, divergent thoughts are put together.

- Idea organizing: Different ideas are compared, analyzed, and put into a category using organized discussions and arguments.

- Intellectual convergence: At this phase, intellectual synthesis and consensus take place. Agreeing to disagree is embraced; assignments are made in the form of essays as well as joint pieces of work (Harasim, 2017).

$\mathrm{OCL}$ is also based on social constructivism. This is because the learners are encouraged to solve problems collaboratively by way of discourse. The major aspect of $\mathrm{OCL}$ is that the work of a teacher is to facilitate the process of learning. In other constructivism theories, the teacher is an active facilitator of knowledge acquisition. Due to the significance of the duties of the teacher, online collaborative learning is not easy to scale up. OCL is mainly suited for smaller instructional environments, unlike connectivism, which is mainly large-scale based. Therefore, when seeking commonality among online education theories, OCL becomes 
significantly important. Several theories are closely related to online education. However, instead of coming up with many theories and trying to keep up with the major aim of the research, it is essential to determine whether an integrated or unified theory of online education is something that can be adopted and successfully implemented.

Main Objective: The main goal of the research is to find out whether Ghanaian international students in China are satisfied with the "new" e-learning adopted by all institutions of higher education as a result of COVID-19.

\section{Research Questions}

RQ1. What is the student's Perception of the effectiveness and credibility of Course Content for online learning?

RQ2. What is the level of students' knowledge of the CONVID-19 pandemic?

RQ3. How much satisfied are the students with the "Learning Resources" available?

RQ4. What are the expected challenges that students are likely to encounter during the online teaching and learning?

\section{METHODOLOGY}

This study used a purposive online survey of Ghanaian international students as participants for this study. The reason to use Ghanaian international students is that online learning is not so much developed in Ghana. Most of the international students coming from developing countries, including those in Ghana, were used to the traditional face-to-face mode of teaching and learning (Ananga \& Biney, 2017). Hence as first-timers, they were likely going to encounter some challenges. According to Toepoel (2017), online survey is one of the best means of the cutting-down cost when carrying out a study but at the same time serves as an effective way of getting authentic data from the online population. The objective of this study was to ascertain how Ghanaian international students in Beijing, China, are responding to the online learning adopted by all institutions of higher education as a result of COVID-19.

\section{Sampling}

The population for the study was the WeChat group of Ghanaian students who are participating in online learning in various higher educational institutions of China. The sampled group is made up of 360 students on the WeChat group. Still, with 330 active members (members in the group who actively participate in commenting, asking the question, sharing various information in the group to ensure that group remains active), all the active participants were targeted for the survey. Before subjecting the participants to the esurvey, a request was made to both the group administrators and members on the intent of the survey, and the link of the survey was shared via the WeChat group platforms.

For the scope of data collection, the researchers applied the survey item. Respondents who are participating in the online learning programs in various universities were invited through the WeChat platform to complete the sampling. Data were collected over one month; March to Mind-April 2020 from Ghanaian international students at the various institutions in China. The survey took the participants about 9 minutes to complete. A bi-weekly reminder strategy was used to inform the participants who had not completed the survey to do so. The questionnaire was adapted according to e-learning requirements and is around four dimensions namely: effectiveness and credibility of online learning, availability of learning resources, students' challenges with the issues of the e-learning as well as questions on students' knowledge on COVID19. A total of 330 questionnaires were distributed, which consist of 35 Likert scale survey items, sorted into four dimensions/factors. Out of 330 survey questionnaires administered, 315 survey questionnaires were responded to; nevertheless, 315 were applicable since 15 questionnaires remained unfinished or mistakenly filled out. This translates to a response rate of 95\%. Creswell \& Poth (2016) and Babchuk (2017), cited that any study with a response rate of $50 \%$ and above is appropriate for analysis, hence our response rate of $95 \%$ was very excellent to continue with the analysis. Survey Monkey software was used to get data for the research. The results were recorded on a 5 point Likert scale. The range was from strongly disagree to agree strongly. A mean score was used to evaluate students' responses to each dimension. 
Table 1. Age group of Respondents

\begin{tabular}{ccccc}
\hline & Frequency & Percent & Valid Percent & Cumulative Percent \\
\hline $21-30$ & 78 & 24.7 & 24.7 & 29.0 \\
\hline $31-40$ & 175 & 55.5 & 55.5 & 84.5 \\
\hline $41-50$ & 59 & 18.7 & 18.7 & 99.3 \\
\hline 50 and above & 3 & .9 & .9 & 100.0 \\
\hline Total & 315 & 100.0 & 100.0 & \\
\hline
\end{tabular}

Table 2. Sex of Respondents

\begin{tabular}{ccccc}
\hline & Frequency & Percent & Valid Percent & Cumulative Percent \\
\hline Female & 129 & 40.9 & 40.9 & 40.9 \\
\hline Male & 186 & 59.1 & 69.1 & 100.0 \\
\hline Total & 315 & 100.0 & 100.0 & \\
\hline
\end{tabular}

Table 3. Educational Level

\begin{tabular}{ccccc}
\hline & Frequency & Percent & Valid Percent & Cumulative Percent \\
\hline Diploma & 15 & 4.7 & 4.7 & 4.7 \\
\hline Bachelor's degree & 80 & 25.3 & 25.3 & 30.0 \\
\hline Masters and above & 220 & 69.8 & 69.8 & 100.0 \\
\hline Total & 315 & 100.0 & 100.0 & \\
\hline
\end{tabular}

\section{RESULTS}

The results of the research were discussed in detail based on the questions that were provided. The purpose of the study was to investigate Coronavirus (COVID-19) and Online Learning in Higher Educational Institutions in the analysis, data from questionnaires were coded and analyzed by the use of version 20 of SSPS software. The software was used to excellent reliability among multiple measures of variables of the study. During the study, 330 questionnaires were given out to the respondents, out of which 315 were valid.

\section{Age Distribution of Participants}

Table 1 of the study illustrates the total number of respondents which is 315 . The study sought to determine the age of the respondents. $24.7 \%$ of the respondents were between $21-30$ years, $55.5 \%$ were 31 $40 \%, 18.7 \%$ were between $41-50$ years and $.9 \%$ of the respondents were 50 and above years old.

\section{Sex of Respondents}

Table 2 of the study describes the whole number of respondents along with the frequency of two options, first is 'Female' 83 with the percentage of 30.9 the second is 'Male' 186 with a percentage of 69.1.

\section{Educational Qualification of Participants}

Table 3 of the study presents the total number of respondents which is 269 . The table also has the frequency of each level such as 'Diploma' 9 (3.3\%) next 'Bachelor's degree' 62 (23.0\%) then 'Masters and above' $198(73.6 \%)$.

\section{Reliability of the Entire Instrument}

Table 4 shows the reliability of the entire instrument. There were 05 Likert subscales for 04 dimensions, the questionnaire consisted of 35 items in all, Crobach's Alpha reliability was recorded for each subscale ranging from 0.831 to 0.923 , and overall reliability of 0.981 shows that the instrument yielded consistent since reliability is accepted when the Crobach's Alpha is greater than 0.70 . This indicates that one can rely on the results of this instrument. 
Table 4. The Reliability

\begin{tabular}{ccc}
\hline Variables & Items & Reliability \\
\hline Students Perception of the Effectiveness and Credibility of Course Content for Online Learning & 7 & 0.831 \\
\hline Level of Student's Knowledge of COVID-19 Pandemic & 9 & 0.923 \\
\hline How Much Satisfied are the Students with “Learning Resources" Available & 11 & 0.877 \\
\hline Expected Challenges the Students are likely to Encounter during the Online Teaching And Learning & 8 & .860 \\
\hline Completed instrument & $\mathbf{3 5}$ & $\mathbf{0 . 9 8 1}$ \\
\hline
\end{tabular}

Table 5. Mean Scores of Subscales Variables

\begin{tabular}{ccc}
\hline Variables & \multicolumn{2}{c}{ Sample } \\
\cline { 2 - 3 } & Mean & CV \\
\hline Student's Perception of the Effectiveness And Credibility of Course Content for Online Learning & 3.77 & .23 \\
\hline Level of Student's Knowledge Of COVID-19 Pandemic & 3.72 & .22 \\
\hline How much Satisfied are the Students with "Learning Resources" Available & 3.74 & .24 \\
\hline Expected Challenges that Students are likely to Encounter During the Online Teaching and Learning & 3.51 & .29 \\
\hline
\end{tabular}

Table 6. Score of each point of the Likert scale

\begin{tabular}{ccccc}
\hline Strongly agree & Agree & Neutral & Strongly disagree & Disagree \\
\hline 1 & 2 & 3 & 4 & 5 \\
\hline
\end{tabular}

\section{Mean Scores of Subscales Variables}

In Table 5, as discussed already, reliability entails the level upon which an instrument used to make the measurements have variable errors that vary every time the use of the instrument successfully measures a unit. The Table also contains the mean of each instrument and the cumulative variance of each instrument.

The questionnaire consisted of 04 subscales and used 5 points Likert Scale, following is Table 6 , showing a score of each point of the Likert scale.

\section{DISCUSSIONS}

\section{Student's Perception of the Effectiveness and Credibility of Course Content for Online Learning}

Students perceived online learning as very useful as most of them highly agreed to the effectiveness of online learning. A mean score of 3.77and a cumulative variance of .23has been recorded, which again shows that students are positively contributing to the ineffectiveness of online learning.

\section{Level of Students' Knowledge of COVID-19 Pandemic}

This pertains to students' knowledge of the COVID-19 pandemic. The majority of students know deadly COVID-19. A mean score of 3.72 shows students' high satisfaction with this dimension.

\section{How much Satisfied are the Students with "Learning Resources" Available}

Learning refers to the use of texts, software, videos together with some other forms of materials recommended by the teacher to help a student meet the required expectations of learning. A mean of 3.74 shows that students are satisfied with the learning resources available.

\section{Expected Challenges Students are likely to Encounter during the Online Teaching and Learning}

In the course of the study, one major challenge of online learning is meant to impart a sense of togetherness in a community in an online environment. Other issues Students identified the high cost of internet data for students who are currently outside China. The difference in time zone was also recognized as a severe challenge to online learning. At the same time, students who were still within China and were staying on the various university dormitories complain of the slow nature of the internet. This subscale had a Mean score of 3.51 . 


\section{CONCLUSIONS}

A total of 315 participated in the study, $69.1 \%$ were males, and $30.9 \%$ females. The majority of the respondents belonged to $31-40$ years of age, with $73.6 \%$ pursuing Masters and Ph.D. degrees. The reliability of all subscales and the overall scale was found higher, which substantiated the reliability of the instrument. The survey found out that the learners were contented with online learning education provided by Institutions of Higher Education in Beijing, China. Student's Perception of the effectiveness and credibility of the online learning program yielded the highest mean score (3.77), and challenges that students encounter during the online Teaching and Learning received lowest mean score (3.51); on a 05 point Likert scale these scores are appreciative. Based on the findings, it is clear students are satisfied with the online teaching and learning instituted by various educational institutions of higher learning, despite the few challenges identified.

\section{Implications of the Study}

Throughout the study, it was discovered that among the primary challenges in e-learning is to enhance a sense of community. And to come up with such a community, the findings pointed out the importance of uplifting the level of social interaction and collaboration (Shlossberg \& Cunningham, 2016; Wang \& Hu, 2019). We, therefore, saw the importance of both the teachers and students coming together to formulate ways of interacting and collaborating to create an effective and efficient online community.

A literature review of the study indicates a speedy advancement of the level of technology and how it has influenced the level of online learning. It also points to the way online education is set to influence a number of issues with time. According to evidence provided technology such as the World Wide Web (WWW) and emails have played a significant role in the speedy development of e-learning. Conversely, we argued that the standardization, as well as the inflexibility of online products, is likely to hamper the individualized learning process.

Successful and effective e-learning is mainly depended on how the contents of the course are designed, the contents of the course outline, the interaction between the student and professor as well as the availability of learning materials. Based on our analysis, the study found out that the lecturers much help during the implementation of online learning (Bao, 2020). Teachers facilitate discussions at both individual and group levels. They respond to the questions asked by the learners, design assignments, and examine the learning of the students. It is essential to note that technology may not be able to replace to work of a teacher. It has to be known that they teach a large number of learners but does not satisfactorily receive workload relief and neither do they get the necessary support they need.

\section{Limitations}

The study was performed on a relatively small population, thus only Ghanaian Students in Beijing, China. It limits our ability to generalize from this study that over half a million international students in Beijing, China duly have informed knowledge of COVID-19 and support the implementation of online learning in various institutions of higher education. Secondly, a large scale survey is needed that would guarantee a fair representation of the target population of all international students studying in higher educational institutions.

\section{Future Research}

E-learning is set to grow at high speed. And if that is the case, research must be carried out on a large scale to facilitate the improvement of methods of teaching and learning. Currently, there exists a void that needs to be filled. Perhaps future research should be mainly concerned in carrying out an in-depth analysis of the practices that should be adopted such as online instruction practices, implementation process as well as a more detailed analysis procedure for course design. The study aimed to get the view and perspectives of the learners, especially the students who have never been in computer class learning and are interested in enrolling for the online programs due to the COVID-19 pandemic. It has to be understood that there is no empirical evidence in the already carried out research which reveals whether e-learning has actualized the academic goals of the students. 
E-learning is growing, and the trend is likely to continue as more institutions are expected to join the rest in offering online courses to the ever-growing number of students. To add to that, the research should also look at the number of students enrolling for the online studies for an instant the undergraduate, graduate, and doctorate levels.

According to Wang and Hu (2019), E-learning is a better alternative for the learners, and the researchers should be able to look for ways of making it more focused on thinking and creation. It should be understood that most online courses are dictated by technology (Donitsa-Schmidt \& Topaz, 2018; Garcia \& Badia, 2017). To be able to enhance intellectual rigour as well as the development and individual perspectives, a more indepth investigation must be explored to find out the use of technology and software during the implementation process. The mode of teaching should be able to keep the students engaged. The other aim of the study was to establish how group designs can positively influence social interaction and some form of the learning community. This is in consideration of the different personalities of group members, varied learning styles, and different levels of skills. Initial studies mainly focused on examining the postings that were sent by the interviewees. With the enhancement of tools, researchers need to find out the roles played by technological devices in the promotion of a highly efficient and effective social interaction as well as the expansion of a learning environment. For instance, the researchers need to find out ways of making use of video conferencing and Skype. Making use of social networks and virtual reality environment can significantly enhance the e-learning process.

\section{REFERENCES}

Ananga P., \& Biney, I. K. (2017). Comparing face-to-face and online teaching comparing face - to - face and online teaching. MIER Journal of Educational Studies, Trends \& Practices, 7(2), 165-179.

Babchuk, W. A. (2017). Book review: Qualitative research: a guide to design and implementation (4th ed.), by s. B. Merriam and e. J. Tisdell. Adult Education Quarterly, 67(1), 71-73. https://doi.org/10.1177/0741713616671930

Bao, W. (2020). COVID -19 and online teaching in higher education: A case study of Peking University. Human Behavior and Emerging Technologies, 2(2), 113-115. https://doi.org/10.1002/hbe2.191

Creswell, J. W., \& Poth, C. N. (2016). Qualitative inquiry \& research design: Choosing among five approaches. (4th ed). SAGE Publications.

Donitsa-Schmidt, S., \& Topaz, B. (2018). Massive open online courses as a knowledge base for teachers. Journal of Education for Teaching, 44(5), 608-620. https://doi.org/10.1080/02607476.2018.1516350

Filius, R. M., Kleijn, R. A. M., Uijl, S. G., Prins, F. J., Rijen, H. V. M., \& Grobbee, D. E. (2019). Audio peer feedback to promote deep learning in online education. Journal of Computer Assisted Learning, 35(5), 607-619. https://doi.org/10.1111/jcal.12363

Garcia, C., \& Badia, A. (2017). Information problem-solving skills in small virtual groups and learning outcomes: IPS skills and learning outcomes. Journal of Computer Assisted Learning, 33(4), $382-392$. https://doi.org/10.1111/jcal.12187

Harasim, L. M. (2017). Learning theory and online technologies. https://ebookcentral.proquest.com/lib/ulaval/detail.action?doclD=4865772

Murphy, M. P. A. (2020). COVID-19 and emergency eLearning: Consequences of the securitization of higher education for post-pandemic pedagogy. Contemporary Security Policy, 1-14. https://doi.org/10.1080/13523260.2020.1761749

Picciano, A. G. (2017). Theories and frameworks for online education: Seeking an integrated model. Online Learning Journal, 21(3). https://doi.org/10.24059/olj.v21i3.1225

Shlossberg, P., \& Cunningham, C. (2016). Diversity, instructional research, and online education. Communication Education, 65(2), 229-232. https://doi.org/10.1080/03634523.2015.1098713

Toepoel, V. (2017). Online survey design. In The SAGE Handbook of Online Research Methods (pp. 184-202). SAGE Publications Ltd. https://doi.org/10.4135/9781473957992

UNESCO. (2020, Match 13). COVID-19 educational disruption and response. Retrieved from https://en.unesco.org/covid19/educationresponse 
UNESCO. (2020). Global Education Coalition-290-million students out school due-COVID-19. In Unesco. https://en.unesco.org/news/290-million-students-out-school-due-covid-19-unesco-releases-first-globalnumbers-and-mobilizes

Wang, H., Pi, Z., \& Hu, W. (2019). The instructor's gaze guidance in video lectures improves learning. Journal of Computer Assisted Learning, 35(1), 42-50. https://doi.org/10.1111/jcal.12309

WHO. (2020). Report of the WHO-China Joint Mission on Coronavirus Disease 2019 (COVID-19). The WHO-China Joint Mission on Coronavirus Disease 2019, February, 16-24. Retrieved from https://www.who.int/docs/default-source/coronaviruse/who-china-joint-mission-on-COVID-19-finalreport.pdf

Yang, F., \& Li, F. W. B. (2018). Study on student performance estimation, student progress analysis, and student potential prediction based on data mining. Computers \& Education, 123, 97-108. https://doi.org/10.1016/j.compedu.2018.04.006

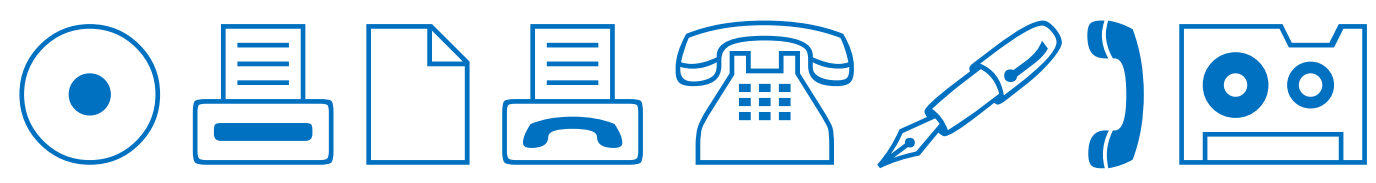

